\title{
MANUFACTURING RESOURCE MANAGEMENT FOR COLLABORATIVE PROCESS PLANNING
}

\author{
Ziqiang Zhou ${ }^{1}$, Mujun $\mathrm{Li}^{2}$, Liguan Shen ${ }^{2}$ \\ 'Mechanical Department, Changshu Institute of Technology, Changshu, China; \\ Email:zzq_hefei@163.com. ${ }^{2}$ Department of Precision Machinery and Precision \\ Intrumentation, University of Science \& Technology of China, Hefei, China.
}

\begin{abstract}
A framework of collaborative process planning (CPP) platform is introduced. For this purpose, manufacturing resource management system should be constructed. The main modular of them are discussed, which include equipment information management, fixture information management, cutting tool information management, process parameter and NC code information management. In the end, the application of how to work on the process planning in virtual enterprise with manufacturing resource based on the CPP is introduced.
\end{abstract}

Key words: Manufacturing resource, Collaborative, Process planning, Simulation.

\section{INTRODUCTION}

With competition in global markets, more and more enterprises seek to make up virtual enterprise or cooperate with each other in the manufacturing process in order to reduce cost of product and increase competitive ability. For this reason, some of the key technologies are developing in the field of collaborative work between enterprise, besides collaborative design, the collaborative process planning (CPP) also very important among them ${ }^{[1-3]}$. With CPP platform engineers whom belong to the different enterprise may be work more efficiently than before, and the manufacturing resource of virtual enterprise will be utilized more optimized. So a distributed manufacturing resource management system is need in the CPP platform.

Please use the following format when citing this chapter:

Zhou, Ziqiang, Li, Mujun, Shen, Liguan, 2006, in International Federation for Information Processing (IFIP), Volume 207, Knowledge Enterprise: Intelligent Strategies In Product Design, Manufacturing, and Management, eds. K. Wang, Kovacs G., Wozny M., Fang M., (Boston: Springer), pp. 926-931. 
Planning

\section{FRAMEWORK OF COLLABORATIVE PROCESS PLANNING PLATFORM}

The framework of CPP platform shown in the Figure.1, which is a multiagent, based collaborative system. Each partner of the virtual enterprise has a manufacturing resource agent which includes equipments information, cutting tools information, material information and etc. On the sever side, a multi-user collaborative sever program is running for the entire request from the client side. It composed of collaborative process planning modular, collaborative NC simulation modular and collaborative discussion modular. The engineers are operating on the client side to do process planning work, they can collaborative discuss the virtual entity of the part, make label on the 2D drawing of the part, and select suited equipment or cutting tools from the manufacturing resource agent. In the fixture design process, engineers can query from the manufacturing resource agent and get needed part or assembly. Each manufacturing resource agent can transform the data to others automatically, and the new work of engineer will be uploading to the manufacturing resource agent after checkup. Finally, the process engineers can make optimized manufacturing process of the part. With NC collaborative simulation modular, engineers can discuss and evaluate the $\mathrm{NC}$ program on the Internet collaboratively. With CPP platform the young engineer will be advantaged from the system and other professional engineer, on the other hand, the partners of the virtual enterprise will be benefited from the sharing manufacturing resource.

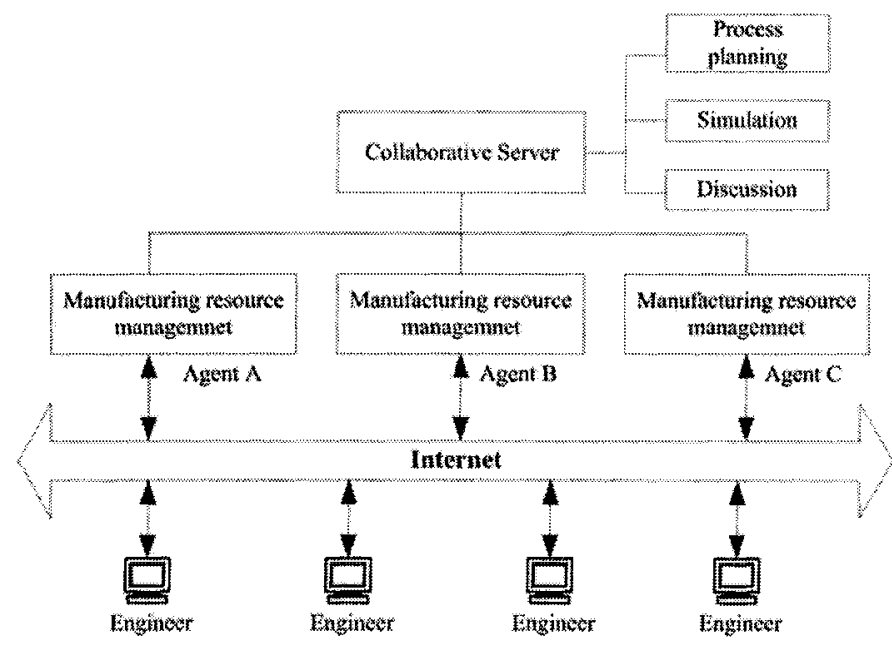

Figure 1. Framework of collaborative process planning platform 


\section{STRUCTURE OF MANUFACTURING RESOURCE AGENT}

The function of manufacturing resource agent is supply rational information for process engineers on the CPP. Four main modular is include: equipment information management, fixture information management, cutting tool information management, process parameter and NC code information management. The resource information is stored with structured data, rule file and $2 \mathrm{D}$ or $3 \mathrm{D}$ entity of the part. The structured data is stored in the database, the rule of the manufacturing knowledge is stored with a special defined rule language file and the $2 \mathrm{D}$ or $3 \mathrm{D}$ entity of the part of other component is stored with standard format such STEP or STL file.

Because the structure of manufacturing resource management is based on the multi-agent, so a controlling modular is used to receive outer assignment and supply information for engineer or other agent. In this modular a universal data interface is defined for data transform.

\subsection{Equipments information management}

All the manufacturing equipments information of the partners within virtual enterprise should be managed in the resource agent. It includes type parameter, precision parameter, working range, and cutting speed of machine tool. All this data is stored in the table of database. The quantity and cost of machine also should be considered. Only by this means, the process engineers can choose cutting machine with high efficiency and low cost. On the other hand, the $3 \mathrm{D}$ models of the machine are also created for the collaborative NC simulation.

\subsection{Fixtures information management}

Fixtures design and manufacture is very important factor in the manufacturing process. The engineers usually start with three options: permanent, modular, and general-purpose fixture. Each of these options has many clamping and locating options of its own. The more standard locating and clamping devices that a designer is familiar with, the more creative he can be. So there are many standardized components in the agent include clamps, locators, supports, studs, nuts, pins, and a host of other elements. The engineers can choose suited components from a intelligent wizard and then download the 3D model from the agent, by this means, the efficiency of fixture design process could be increased, with an electronic white board, engineers can even collaborative discuss the fixture design on the Internet. 


\subsection{Cutting tools information management}

The focus of this modular lies in representing information about cutting tools. That will adequately fulfill the needs of process planning with cutting machine in the virtual enterprise. The flowing data should be contained.

- Parameters of tool components, complete assemblies and tool kits, include dimension, material, and specification, etc.

- Cutting data based on the machining handbook.

- 3D solids with standard format such as STEP, SAT or STL format.

Metal cutting fluids are very important in the process planning, because its characteristics are widely changing, and the cutting quality of the metal part are mostly depend on the cutting fluids. Therefore, the information of cutting fluid also should be contained in the database.

\subsection{Process parameters and NC code information management}

This is the core segment of manufacturing resource management, all the process engineers will benefited from the process parameters information in CPP during their work. In traditional enterprise, the process planning work mostly depend on the individual knowledge of process engineer, so quality of process planning parameters can not be assured rationally. The goal of this modular is describe all the process information and process parameters with standardized format, and stored them in database. The flowing three aspects information should be stored.

- Universal knowledge or rule such as machining sequence, clamping method and so on. With this rules and instructions, process engineer can fix their attention on the deciding rational process of the part of product, and needn't to do great deal of labors consuming work.

- Process information of typical part or product, which will help to create new manufacturing process of the part. The engineer can find a similar part from the database and edit some of the parameter. Moreover, all the process information created by the CPP will be stored in the system automatically.

- All the machining parameter such as rotate speed of spindle, feeding speed, and so on. The parameter of heat treatment also stored in the database. Engineers can acquire optimized parameter with reasoning algorithms.

NC code information of the part also is managed in the system. It include 3D entity file of the part, project information, version information and related process information, etc. the engineer can edit and simulation an $\mathrm{NC}$ 
code collaboratively with partners in other enterprise. The validated NC code can be sent to the CNC machine immediately.

\section{APPLICATION OF MANUFACTURING RESOURCE FOR CPP}

With manufacturing resource of CPP platform, process engineers can work collaboratively on the Internet. Firstly the $2 \mathrm{D}$ or $3 \mathrm{D}$ model of the part will be loaded on the electronic white board for collaborative discussion, in this course, the blue print of manufacturing process will be discussed, and the benchmark of the part, clamping mode, etc. will all be discussed and confirmed. The figure 2 shows the client side of electronic white board. In the next step, the detailed process planning will be confirmed, which include fixture design, process parameter choosing, and $\mathrm{NC}$ code programming. Engineers can design fixture based the blue print from first step on the CAD software, in the working process, they can also transport the drawing of the fixture to the electronic white board with DWG or DXF format just for collaborative discussion. In the process parameter planning choosing, the cutting speed, feeding speed, tool type will all be determined. Then engineers can create the NC code with CAM software, after this step, the NC code is loaded in the collaborative NC simulation modular (show in the figure 3), the simulation modular will load the cutting tool chose from the manufacturing resource and simulate the cutting process collaborative. If there are some mistakes found in the simulation. The NC code will be edit or rework.

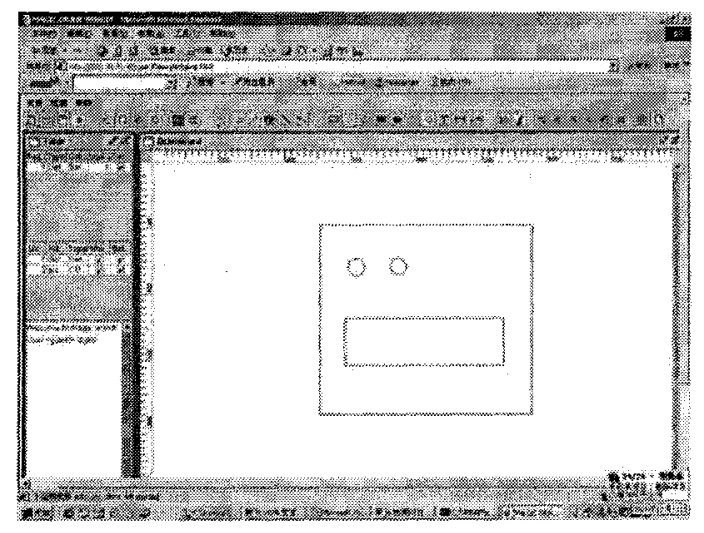

Figure 2. Collaborative discussion on the drawing of part with white board 


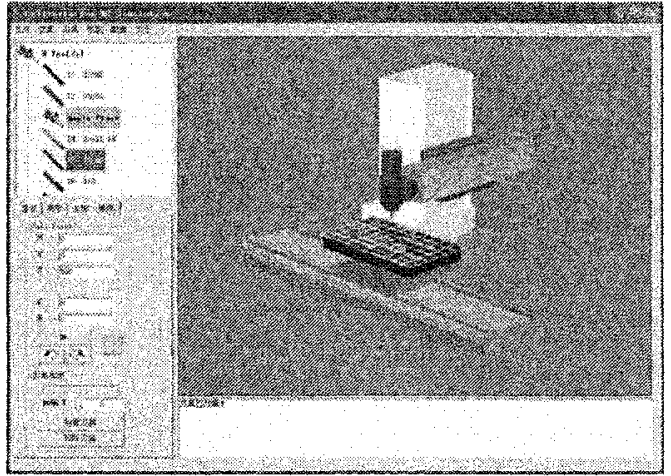

Figure 3. Snapshot of collaborative NC simulation client-side

\section{CONCLUSIONS}

A multi-agent based manufacturing resource management system is constructed for CPP platform. The contents and functions of its main modular are discussed. With CPP platform, engineers can utilize manufacturing resource of the virtual enterprise sufficiently during the process planning. Thus product can be manufactured with better quality and low cost.

\section{REFERENCES}

1. Ziqiang Zhou, Xiaoguang Li , Lianguan Shen, Research of Web-based collaborative modeling using layered feature language, Proceedings of IE\&EM'2002 \& ICeCE' 2002. Sept.19-21, 2002. Beijing, P.R.China.

2. George Q., Huang. Web-based support for collaborative product design review. Computers in Industry, 2002, 48(1): 71 88

3. Jan Kempenaers, Jos Pinte, A collaborative process planning and scheduling system, Advances in Engineering Software 25(1996):3 8

4. Ziqiang Zhou, Xiaoguang $\mathrm{Li}$, etal. The role of Web-based virtual design in the mass customization, Proceedings of the Third International Conference on Electronic Commerce Engineering. Hangzhou, PRC. pp.601-605.

5. Bernhard Jung, Mathias Nousch. Design and Configuration of Furniture Using Internetbased Virtual Reality Techniques. http://www-is.informatik.uni-oldenburg.de / sauer/ puk2000/ papers/jung.pdf

6. Q. Peng, F.R. Hall, P.M. Lister, Application and evaluation of VR-based CAPP system, Journal of Materials Processing Technology, 107 (2000),pp.153 159 